\title{
Warstwy nawęglane - korelacja oznaczeń metodą prądów wirowych i pomiarów twardości
}

\author{
Carburized layers - correlation of indications \\ by eddy current test and hardness measurements
}

\section{Streszczenie}

W kontroli jakości wyrobów po obróbce cieplnej i cieplno-chemicznej stosowane są oznaczenia twardości powierzchniowej. W przypadku warstw nawęglanych pomiary twardości mogą być niewystarczające. Istnieje bowiem ryzyko niewykrycia istotnych zmian struktury warstwy. Celem pracy było zbadanie korelacji wyników oznaczeń twardości metodą prądów wirowych i pomiarów twardości metodą Vickersa. Przedmiotem badań były nawęglane próbki ze stali AMS 6265, różniące się twardością warstwy: 700 HV0,5, 740 HV0,5, 780 HV0,5. Grubość warstwy nawęglanej była jednakowa dla wszystkich próbek i wynosiła 1,2 mm. Wyniki przeprowadzonych badań potwierdzają możliwość oceny twardości powierzchniowej warstw nawęglanych metodą prądów wirowych.

Słowa kluczowe: warstwy nawęglane; twardość powierzchniowa; prądy wirowe
Abstract

In the quality control of products after heat treatment and thermo-chemical treatment indications of surface hardness are used. In the case of carburized layers, hardness measurements may be insufficient. There is a risk that significant changes in the structure of the layer will not be detected. The aim of the study was to investigate the correlation of indications results of the hardness by eddy current test and Vickers hardness measurements. Carburized samples from AMS 6265 steel were tested, they had different surface hardness: 700 HV0,5, $740 \mathrm{HV} 0,5,780 \mathrm{HV} 0,5$. The thickness of the carburized layer was the same for all samples and it was $1,2 \mathrm{~mm}$. The results of the study confirm the opportunity to evaluate the surface hardness of carburized layers by eddy current test.

Keywords: carburized layers; surface hardness; eddy current

\section{Wprowadzenie}

W warunkach produkcyjnych, zgodnie z obowiązującymi normami, stosuje się kontrolę niszczącą wybranych wyrobów z danej partii produkcyjnej. Nie gwarantuje to, że wszystkie wyroby z partii będą wolne od wad. Niewykryte wady, np. strukturalne, mogą prowadzić do awarii podczas eksploatacji, co przedstawiono w pracach $[1 \div 3]$. W przypadku elementów szczególnie odpowiedzialnych, np. stosowanych w lotnictwie, wykonuje się kontrolę wszystkich wyrobów z zastosowaniem metod nieniszczących.

W kontroli jakości wyrobów po obróbce cieplnej i cieplno-chemicznej stosowane są oznaczenia twardości powierzchniowej. Oznaczenia te mają charakter punktowy. Istnieje ryzyko niewykrycia istotnych zmian struktury tą metodą, zwłaszcza w przypadku zróżnicowanych strukturalnie warstw nawęglanych. Nieniszcząca kontrola metodą prądów wirowych (ET, Eddy Current Testing) może stanowić uzupełnienie metod niszczących.

W metodzie prądów wirowych sygnał pomiarowy jest uśredniony, pochodzi z większej powierzchni. Pole powierzchni pomiarowej oraz głębokość wnikania prądów wirowych są zależne od konstrukcji miernika i sond pomiarowych oraz parametrów pomiaru. Wielkość sygnału jest funkcją przewodności elektrycznej i przenikalności magnetycznej materiału badanego. Jest to metoda porównawcza, wymagająca stosowania próbek odniesienia

Mgr inż. Sylwester Jończyk , mgr inż. Adam Kondej, mgr inż. Michał Baranowski, mgr inż. Sylwia Włodarczyk, Tadeusz Samborski - Instytut Mechaniki Precyzyjnej Warszawa.

Autor korespondencyjny/Corresponding author: sylwester.jonczyk@imp.edu.pl 
i wzorcowania. Jej zalety to: wysoka czułość, krótki czas pomiaru oraz możliwość automatyzacji w warunkach pro-

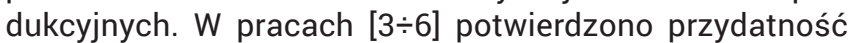
metody ET do badań warstw hartowanych i azotowanych, z wykorzystaniem układu pomiarowego Wirotest + sondy, produkcji IMP.

Struktury warstw nawęglanych mogą być niejednorodne [7]. W badaniach warstw nawęglanych należy uwzględniać jakościową i ilościową ocenę struktury oraz twardość powierzchniową. Istotna jest ocena zróżnicowania austenitu, węglików i struktur perlitycznych [8], ważna jest także twardość rdzenia. Metody badania warstw nawęglanych są przedmiotem norm $[8,9]$.

W pracy [10] pomiary wykonane na próbkach ze stali $16 \mathrm{HG}$, nawęglanych w warunkach laboratoryjnych, wykazały zależność sygnału wiroprądowego od twardości (mierzonej na przekroju) oraz grubości warstwy.

\section{Cel pracy}

Celem pracy było zbadanie korelacji wyników oznaczeń twardości metodą prądów wirowych i pomiarów twardości powierzchniowej metodą Vickersa. Oznaczenia twardości metodą ET wykonano przy różnych parametrach pomiaru.

\section{Przedmiot badań}

Przedmiotem badań było 6 próbek o wymiarach: $\varnothing 32 \mathrm{~mm}$, $\mathrm{h}=11 \mathrm{~mm}$, wykonanych ze stali AMS 6265 (PN12H2N4A). Próbki nawęglano w warunkach półtechnicznych, według parametrów producenta, dla których twardość po procesie powinna wynosić: 700 HV0,5, 740 HV0,5, 780 HV0,5, zaś grubość warstwy 1,2 mm. Pomiary wykonywano po obu stronach próbek, których oznaczenia przedstawiono w tablicy I.

Tablica I. Oznaczenia badanych próbek

Table I. Marks of tested samples

\begin{tabular}{|c|c|c|c|}
\hline $\begin{array}{c}\text { Twardość } \\
\text { HV0,5 }\end{array}$ & Próbka & Strona & $\begin{array}{c}\text { Oznaczenie } \\
\text { próbki }\end{array}$ \\
\hline \multirow{4}{*}{700} & \multirow{2}{*}{$A$} & a & $\mathrm{A} / \mathrm{a}$ \\
\hline & & b & $\mathrm{A} / \mathrm{b}$ \\
\hline & \multirow{2}{*}{$\mathrm{A} 1$} & a & $\mathrm{A} 1 / \mathrm{a}$ \\
\hline & & b & $\mathrm{A} 1 / \mathrm{b}$ \\
\hline \multirow{4}{*}{740} & \multirow{2}{*}{ B } & a & $B / a$ \\
\hline & & b & $B / b$ \\
\hline & \multirow{2}{*}{ B1 } & a & $\mathrm{B} 1 / \mathrm{a}$ \\
\hline & & b & $\mathrm{B} 1 / \mathrm{b}$ \\
\hline \multirow{4}{*}{780} & \multirow{2}{*}{ C } & a & $\mathrm{C} / \mathrm{a}$ \\
\hline & & b & $\mathrm{c} / \mathrm{b}$ \\
\hline & \multirow{2}{*}{$\mathrm{C} 1$} & a & $\mathrm{C} 1 / \mathrm{a}$ \\
\hline & & $b$ & $\mathrm{C} 1 / \mathrm{b}$ \\
\hline
\end{tabular}

\section{Metodyka badań}

Oznaczenia metodą prądów wirowych wykonywano Wirotestem 302 (nr egzemplarza: 302/001/2007) wraz z sondami stykowymi o częstotliwości pracy od $3 \mathrm{kHz}$ do $4 \mathrm{MHz}$. Próbka A/a była próbką wzorcową (próbką odniesienia), z którą porównywano pozostałe próbki.

Do dokładnego scharakteryzowania próbek wykonano pomiary twardości powierzchniowej metodą Vickersa twardościomierzem Struers DuraScan 70 przy obciążeniach: HV0,1, HV0,5, HV1, HV2, HV5.

\section{Wyniki badań}

Na rysunku 1 przedstawiono wyniki średnie oznaczeń wiroprądowych wykonanych czterema sondami na trzech badanych próbkach w zależności od twardości nominalnej próbek HV0,5, podanej przez dostawcę.

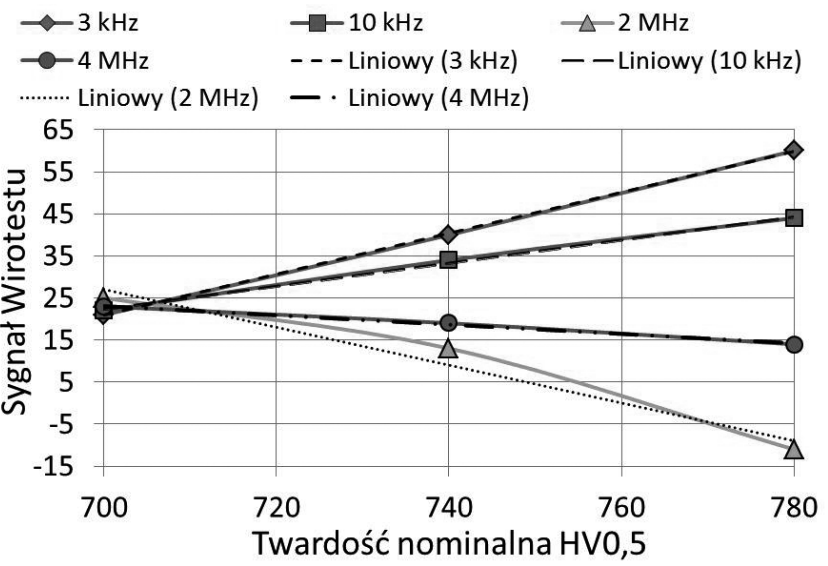

Rys. 1. Zależność sygnału Wirotestu z sondami o różnej częstotliwości pracy (dane średnie) od twardości nominalnej HV0,5

Fig. 1. The dependence of the Wirotest signal with different frequency probes (average data) and the nominal HV0,5 hardness

Zależność sygnału Wirotestu, wyznaczonego czterema sondami, od twardości nominalnej próbek ma charakter prostoliniowy - na co wskazują linie trendu. Kąt nachylenia linii trendu jest zależny od częstotliwości pracy sondy.

Badania potwierdziły zależność sygnału wiroprądowego od twardości HV0,5 badanych próbek o tej samej grubości nominalnej warstwy nawęglanej.

Na rysunku 2 zestawiono sygnały Wirotestu po obu stronach 6 próbek. Przedstawiono wyniki pomiarów sondami o częstotliwości nominalnej $3 \mathrm{kHz}$ i $10 \mathrm{kHz}$.

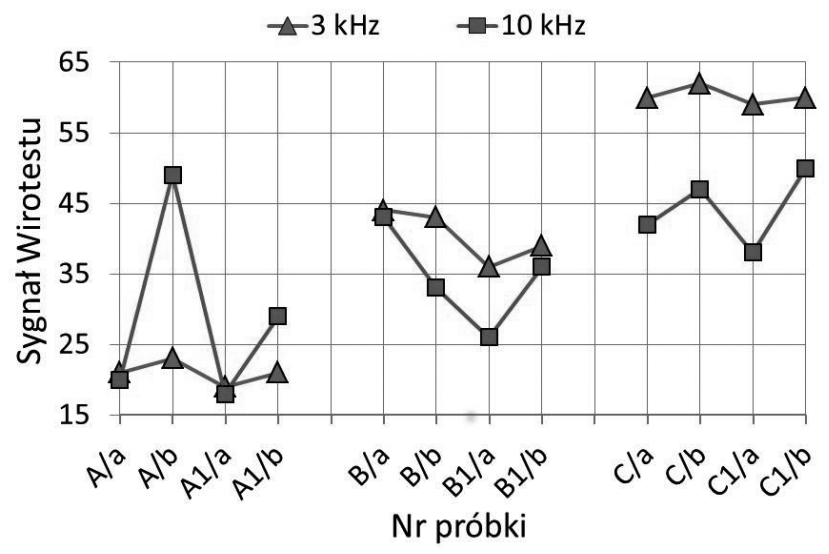

Rys. 2. Zestawienie sygnałów Wirotestu (sonda $3 \mathrm{kHz}$ i $10 \mathrm{kHz}$ ) po dwóch stronach 6 próbek

Fig. 2. Wirotest signals (probe $3 \mathrm{kHz}$ and $10 \mathrm{kHz}$ ) on both sides of 6 samples 
Największe różnice wskazań Wirotestu 302 między stronami a i b poszczególnych próbek uzyskano przy pomiarze sondą $10 \mathrm{kHz}$. Dla próbki A zarejestrowano największą różnicę spośród wszystkich badanych próbek.

$\mathrm{Na}$ rysunku 3 przedstawiono oznaczenia wiroprądowe wykonane wszystkimi badanymi sondami po dwóch stronach próbki $A 1$.

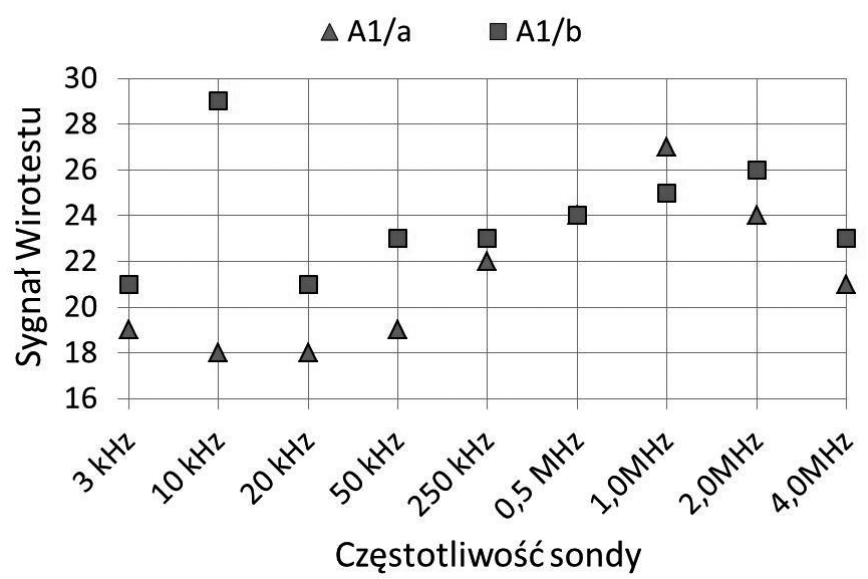

Rys. 3. Sygnał Wirotestu dla sond o różnej częstotliwości pracy. Pomiar stron a i b próbki A1

Fig. 3. Wirotest signal for probes with different frequency. Measurement of $a$ and $b$ sides for sample $A 1$

Największe różnice właściwości stron a i b próbki $A 1$ ujawniono sondą $10 \mathrm{kHz}$. Przy właściwym doborze sond jest możliwość wykrywania różnic strukturalnych warstw nawęglanych. Przedstawione wyniki wskazują na możliwość powstania warstw o zróżnicowanej strukturze.

Pomiary twardości metodą Vickersa wykonano przy obciążeniach: HV0,1, HV0,5, HV1, HV2, HV5, na 12 powierzchniach badanych próbek. W tablicy II przedstawiono wyniki pomiarów próbek A i A1 o twardości nominalnej 700 HV0,5. Są to dane średnie z 5 pomiarów.

Stwierdzono zróżnicowanie twardości powierzchniowej dla zbioru czterech powierzchni dwóch próbek o nominalnej twardości $700 \mathrm{HV0,5.}$

$\mathrm{Na}$ rysunku 4 przedstawiono wyniki średnie pomiarów twardości HV0,5 badanych próbek. Pomiary twardości potwierdzają duże zróżnicowanie próbek, zarówno dla poszczególnych stron, jak i między próbkami. Zróżnicowanie wykrywano także przy zwiększonej liczbie pomiarów.
Widoczne jest podobieństwo oznaczeń twardości metodą prądów wirowych i pomiarów twardości HV0,5 dla badanych próbek (rys. 2 i 4).

$\mathrm{Na}$ rysunku 5 zestawiono wyniki oznaczeń wiroprądowych dla 12 powierzchni, badanych sondą o częstotliwości $1 \mathrm{MHz}$ w funkcji średnich wartości twardości HV5.

Linia trendu z wykresu (rys. 5) wskazuje na zależność sygnału Wirotestu od wartości średnich twardości powierzchniowej.

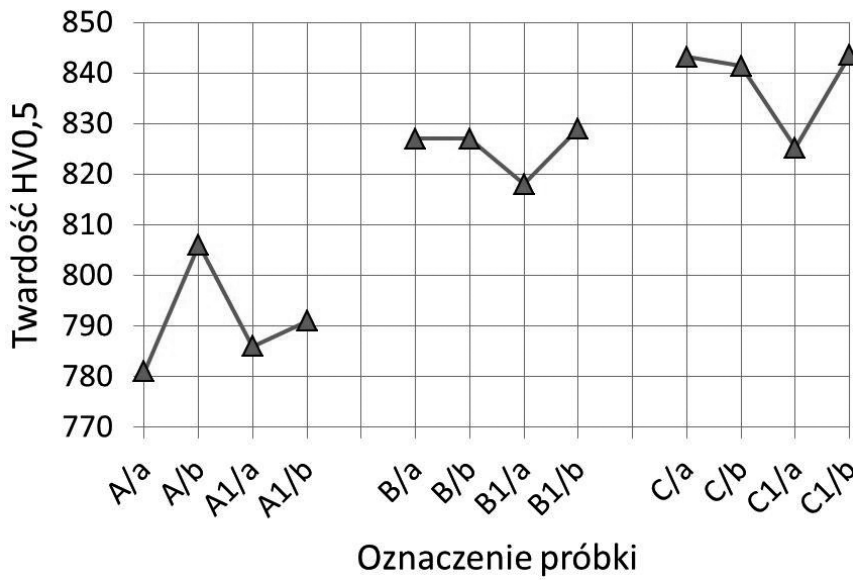

Rys. 4. Wyniki średnie pomiarów twardości HV0,5 dla badanych próbek Fig. 4. The average results of HV0,5 hardness measurements for the tested samples

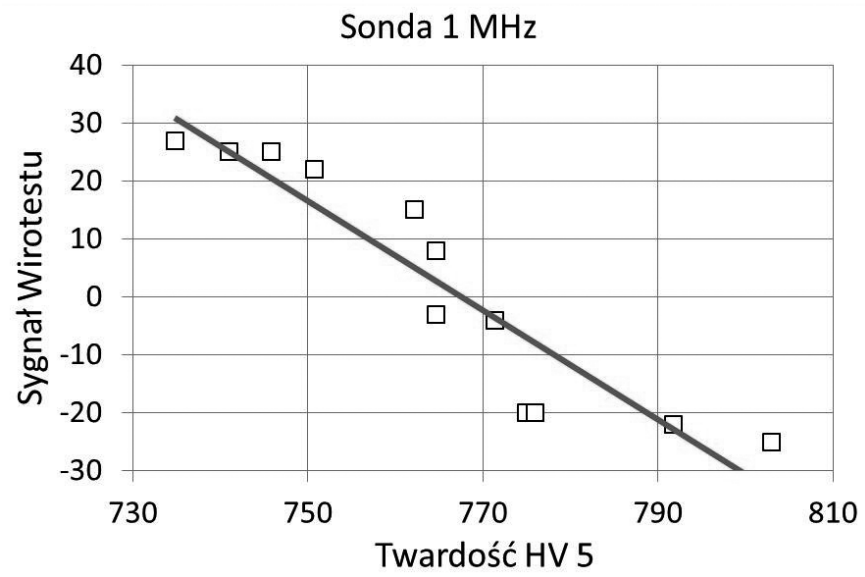

Rys. 5. Zależność sygnału Wirotestu z sondą $1 \mathrm{MHz}$ od twardości HV5 badanych 12 powierzchni

Fig. 5. The dependence of the Wirotest signal with $1 \mathrm{MHz}$ probe and HV5 hardness of 12 tested surfaces

Tablica II. Wyniki pomiarów twardości powierzchniowej HV0,1 i HV0,5 dla próbek A i A1

Table II. The measurements results of the surface hardness HV0,1 and HV0,5 for samples $A$ and $A 1$

\begin{tabular}{|c|c|c|c|c|}
\hline \multirow{2}{*}{ Oznaczenie próbki } & \multicolumn{2}{|c|}{ Twardość HV0,1 } & \multicolumn{2}{c|}{ Twardość HV0,5 } \\
\cline { 2 - 5 } & Średnia & $\begin{array}{c}\text { Odchylenie } \\
\text { standardowe }\end{array}$ & Średnia & $\begin{array}{c}\text { Odchylenie } \\
\text { standardowe }\end{array}$ \\
\hline A/a & 824,0 & 10,7 & 781,6 & 7,3 \\
\hline A/b & 863,0 & 5,5 & 805,8 & 1,8 \\
\hline A1/a & 839,4 & 13,6 & 785,8 & 6,4 \\
\hline A1/b & 833,8 & 16 & 791,4 & 3,6 \\
\hline
\end{tabular}




\section{Wnioski}

1. Nawet w precyzyjnie prowadzonym procesie nawęglania możliwe jest otrzymanie warstw o zróżnicowanej twardości powierzchniowej.

2. Przedstawione wyniki oznaczeń twardości, wykonanych Wirotestem 302 i sondami o różnej częstotliwości pracy, oraz pomiary twardości metodą Vickersa potwierdzają możliwość oceny twardości powierzchniowej warstw nawęglanych metodą prądów wirowych.

\section{Badania realizowano w ramach projektu badawczego PBS3/B/40/2015 „AirLot” pt. „Opracowanie nieniszczących metod charakteryzacji warstw nawęglanych w kołach zębatych".}

\section{Literatura}

[1] K. Pietrzak, A. Klasik, K. Makowska, D. Rudnik, P. Lasota: Nierównomierność zużycia wałków rozrządu, Inżynieria Powierzchni, nr 1, s. 48-55, 2016

[2] S. Jończyk, T. Samborski, S. Włodarczyk: Nieniszczące badania metodą prądów wirowych w odniesieniu do pomiarów twardości HV jako komplementarna kontrola jakości wyrobów mosiężnych, Inżynieria Powierzchni, nr 1, s. 18-23, 2016.

[3] S. Jończyk, T. Babul, S. Włodarczyk: The selected measurements problems in the aspect of the non-destructive testing of the gear wheels and the other parts, Advances in Material Science, vol. 14, p. 92-101, 2014.

[4] S. Jończyk, T. Samborski, S. Włodarczyk: Możliwość zastosowania metody prądów wirowych do kontroli jakości warstw azotowanych, Inżynieria Powierzchni, nr 2, s. 1-6, 2014.

[5] T. Babul, S. Jończyk, T. Samborski: Ocena lokalnych wad mikrostruktury - korelacja wyników pomiarów wiroprądowych i oznaczeń twardości, Przegląd Spawalnictwa, nr 3, s. 21-27, 2014.
[6] T. Babul, S. Jończyk, T. Samborski, S. Włodarczyk: Wykrywanie niejednorodności materiału i lokalnych zmian mikrostruktury metodą prądów wirowych, Przegląd Spawalnictwa, nr 12, s. 25-28, 2013.

[7] K. Jakubowski, L. Klimek, Ad. Rzepkowski, An. Rzepkowski: Metodyka badań parametrów technologicznych warstw wierzchnich otrzymywanych w procesach dyfuzyjnych część I, Inżynieria Materiałowa, nr 3 , s. $407-410,2006$.

[8] PN-EN ISO 2639 „Stale. Określenie i sprawdzanie grubości warstw nawęglonych i zahartowanych".

[9] BN-71/1549-10 „Wzorce struktur nawęglonych i rdzenia”.

[10] S. Jończyk, A. Szczepański, K. Niedźwiedzki: Nieniszczący pomiar grubości warstwy nawęglonej oraz twardości powierzchniowej uzębienia koła zębatego, Inżynieria Powierzchni, nr 2, s. 19-23, 2016. 